\title{
Lacunas da educação infantil
}

Ana Lúcia Soares da Conceição Araújo

Professora da UFBA

Mestre em Educação pela Universidade do Estado da Bahia

\section{Resumo}

O presente trabalho é um recorte de pesquisa do mestrado de Educação, da Universidade do Estado da Bahia a partir das demandas cotidianas de famílias que não possuem poder de escolha como apregoado pelo discurso neoliberal, que acirrou a desregulamentação do Estado e a transferência de responsabilidade das políticas sociais para a sociedade civil. Constituiu-se como objetivo principal do estudo compreender a relação entre a efetivação das políticas públicas para a Educação Infantil e as instituições educativas, sem fins lucrativos (creches comunitárias), na garantia do acesso, ampliação e permanência qualitativa na ação de educar-cuidar das crianças de 0 a 6 anos.

Palavras-chave: Educação Infantil; criança; política pública.

\begin{abstract}
The present work is a cutting of research of the master's degree of Education, of the University of the State of Bahia starting from the daily demands of families that don't possess to can of choice how divulged by the neoliberal speech, that it incited the deregulation of the State and the transfer of responsibility of the social politics for the civil society. It was constituted as main objective of the study to understand the relationship among the to execute of the public politics for the Infantile Education and the educational institutions, without lucrative ends (community day cares), in the warranty of the access, enlargement and qualitative permanence in the action of educatetaking care of the children from 0 to 6 years old.
\end{abstract}

Keywords: Child Education; child; public politics. 


\section{Introdução}

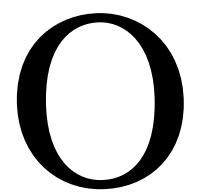

presente artigo busca discutir o papel do Estado em relação à expansão, o acesso e a permanência qualitativa da Educação Infantil, após a prerrogativa desse direito ser prescrito na Constituição de 1988 e a LDB n 9.394/96. Para as crianças de classes sociais desfavorecidas, essa não é uma condição de opção, mas um direito imprescindível para garantia de uma existência digna.

Nas décadas de 1970 e 1980, período de maior abertura política e emergência das tensões sociais latentes no Brasil, intensificaram-se as reivindicações por creches. O movimento feminista exigiu uma nova configuração para o seu atendimento, não mais como a proposta inicial com a qual se destinava assistencialista-custodial, mas para que assumisse um caráter educacional como um direito da criança de 0 a 06 anos e dever do Estado.

A partir da década de 1990, outros instrumentos legais foram formulados na tentativa de reiterar a elevação das crianças como sujeitos sociais. O Estatuto da Criança e do Adolescente, Lei ${ }^{0}$ 8.069/90, foi o primeiro documento a reafirmar o que estava postulado na Constituição Brasileira de 1988: a importância de priorizar a formulação e execução de políticas sociais públicas para infância, como prescrito no art. $4^{\circ}$, parágrafo único. No que tange ao setor educacional, dispõe que a criança tem direito à educação, a fim de proporcionar o pleno desenvolvimento de sua pessoa e o preparo para cidadania, com acesso à instituição pública, gratuita, perto de sua residência. Reforça, ainda, a necessidade de atendimento em creches e pré-escolas para crianças de 0 a 06 anos.

Os anos 90 foram marcados por mudanças sociais significativas no plano global, cristalizando as políticas neoliberais de forma mais efetiva nos países em desenvolvimento, principalmente com as orientações das instituições financeiras multilaterais, exercendo um colonialismo camuflado e sutil como "as guardiãs dos pobres”. As políticas sociais passam a ser o 
foco para a erradicação da pobreza e a Educação assume um papel importante como mecanismo de manobra para as alterações estruturais nos países periféricos. Inicia-se com mais intensidade, como corrobora Peroni (2003), uma era marcada por política social sem direitos sociais.

No Brasil, essa força dos organismos internacionais é traduzida em várias reformas que interferiram na política educacional, dentre as quais podemos citar o Plano de Reforma do Estado, apresentado por Pereira (1995), que buscava desonerar o Estado com as políticas sociais, designando-lhe uma função de regulador e não mantenedor.

A proposta dessa reforma trazia três eixos norteadores: $a$ privatização, a terceirização e a publicização dos serviços públicos prestados pelo o Estado. Pereira (1999) define a privatização como a forma de o Estado transferir para o setor privado as atividades que podem ser controladas pelo mercado com a venda de empresas estatais. A terceirização como uma forma de transferir, para o setor privado, serviços auxiliares ou de apoio com a contratação de empresas terceirizadas mediante licitação pública. E, por último, a publicização que consiste na transferência para o setor público não estatal dos serviços sociais e científicos prestados pelo Estado. De acordo com Pereira (1999), essa transição do papel do Estado geraria a transformação de organização estatal em organização social de direito privado, pública não estatal. Partindo dessa premissa, ao elencar os serviços que seriam desonerados pelo Estado, a creche aparece, com clareza, como um dos itens da educação:

\footnotetext{
No meio, entre as atividades exclusivas de Estado e a produção de bens e serviços para o mercado, temos hoje, dentro do Estado, uma série de atividades na área social e científica que não lhes são exclusivas, que não envolvem poder de Estado. Incluem-se nesta categoria as escolas, as universidades, os centros de pesquisa científica e tecnológica, as creches, os ambulatórios, os hospitais, entidades de assistência aos carentes, principalmente aos menores e aos velhos [...]. (PEREIRA apud PERONI, 1997, p.12).
}

A publicização é o aspecto que mais prejudica a consolidação da Educação Infantil como política pública. Se o Estado atendia de forma 
limitada à demanda existente, jogando para a sociedade civil a responsabilidade por sua implementação, com a possibilidade de publicizala a concretude para o acesso e permanência qualitativa das crianças oriundas das famílias desprovidas de recursos ficou ainda mais distante do cumprimento pleno do poder público estatal.

Ainda no turbilhão das mudanças da década de 1990 que influenciaram na redefinição do papel do Estado, foi criada a nova Lei de Diretrizes e Bases da Educação Nacional, nº 9.394/96, com vistas a materializar algumas políticas educacionais. A Educação Infantil aparece como primeiro nível da educação básica. O Estado, entretanto, coloca-se no dever de ofertá-la de forma gratuita, mas não postula como obrigatoriedade de sua função, como nos demais níveis de ensino. ${ }^{1}$

Como podemos perceber, por essa breve trajetória para a educação das crianças de 0 a 6 anos no Brasil, o distanciamento em relação aos aparatos legais e a realidade concreta continua. Como atender à demanda existente, se na LDB o próprio Estado posiciona-se omisso em prover um bem social, que é a necessidade de acesso das crianças dessa faixa etária à Educação Infantil?

A legitimação das instituições, sem fins lucrativos, que investem na educação - entidades comunitárias, filantrópicas e confessionais, como prescrito no artigo 213 da Constituição de 1988, anuncia uma ambiguidade no papel do Estado por denotar uma omissão consentida pelo poder público, uma vez que o desobriga de assegurar a integralidade de acesso e permanência qualitativa na Educação Infantil.

Somado a isso, como pontua Bastos \& Peixoto (1991), as alternativas encontradas pela população para assumir para si, total ou parcialmente, a responsabilidade do Estado, são marcadas pela precariedade de condições infraestruturas para manutenção contínua do serviço, por uma mão-de-obra

${ }^{1}$ Conforme artigo Art. 4, que estabelece é dever do Estado com a educação pública será efetivado mediante a garantia de:I - ensino fundamental, obrigatório e gratuito[...];II progressiva extensão da obrigatoriedade e gratuidade ao ensino médio;IV - atendimento gratuito em creches e pré-escolas às crianças de zero a seis anos de idade 
muitas vezes despreparada, e pela ausência de uma proposta que associe o educar e o cuidar de uma forma que respeite o desenvolvimento das crianças.

Essas inquietações estão atreladas, também, ao caráter público e privado da educação brasileira. A Educação Infantil, como parte da educação básica atual, está inserida nessa relação contraditória, a qual, ao longo dos anos, sempre esteve interpenetrada: espaços públicos e privados, sem consumar-se como um direito de todas as crianças de 0 a 06 anos e como política pública estatal. É possível que a minimização do Estado, imposta pelas políticas neoliberais na nova fase do capitalismo, deixe essa lacuna para a educação da criança pequena de forma mais visível, uma vez que abre caminho para uma educação pública não estatal.

As famílias dos extratos sociais marginalizados de outros bens sociais básicos tentam buscar alternativas, a fim de resgatar um dos seus direitos cerceados: a Educação Infantil pública, gratuita e de qualidade. Dessa forma, diante do exposto, procura-se investigar a seguinte questãoproblema: de que forma as alternativas encontradas pela população de Salvador, em decorrência das lacunas deixadas pela política educacional, configuram-se como uma forma de ampliação, acesso e permanência qualitativa do direito das crianças de 0 a 06 anos na educação inicial?

Constituiu-se como objetivo principal compreender a relação entre a implementação das políticas públicas para a Educação Infantil e as instituições educativas sem fins lucrativos (creches comunitárias), na garantia do acesso, ampliação e permanência qualitativa na ação de educarcuidar das crianças de 0 a 6 anos.

A metodologia foi baseada em uma interpretação dinâmica da realidade, observando nos fatos as contradições, influências históricas, econômicas e sociais $\mathrm{O}$ espaço empírico da investigação foi em São Caetano, bairro do Município de Salvador por constatar constates iniciativas da população a fim de suprir o direito cerceado. 


\section{Desvelando o significado de intervenção}

A história da mobilização por creches e pré-escolas em São Caetano se insere no contexto mais amplo dos movimentos sociais no Brasil, no início dos anos 80, assim, como no âmbito da conjuntura socioeconômica da época. As diferentes instituições comunitárias existentes foram originadas pela luta isolada de algumas mulheres ou do empenho da associação dos moradores, mas sempre partindo da representação feminina com um propósito comum, apesar de buscarem também benefícios pessoais e imediatos: um lugar onde deixar os seus filhos enquanto estavam cumprindo sua jornada de trabalho.

De acordo com Gohn (2005), os movimentos sociais se organizam em função de uma problemática urbana, seja no que tange à habitação, uso do solo ou o acesso aos serviços e equipamentos coletivos de consumo. As creches e pré-escolas enquadram-se, nesta última demanda social, por se caracterizar como um artefato coletivo que presta cuidado e educação às crianças de 0 a 06 anos. A autora aponta três formas básicas de agregação das lutas populares: as sociedades amigos de bairros ou associação de moradores; associação de favelas e as lutas e movimentos específicos pela moradia ou por equipamentos urbanos. Embora as três modalidades reivindiquem em torno de objetos semelhantes, as distinções se operam conforme a sua origem, concepção político-ideológica, o desenvolvimento do processo histórico, as articulações e os encaminhamentos das demandas e o produto resultante de suas ações.

As Sociedades Amigos de Bairros ou Associação de Moradores são caracterizadas por Gohn (2005) pela política da troca de voto para melhoria infraestrutural do bairro, não se desenvolve uma consciência crítica de se reivindicar como um direito ou rebeldia. As ações são efetivadas por um jogo consensual de "bom relacionamento" e clientelismo, as atitudes de exigir ou solicitar são preteridos pelas de favor.

As Associações de Favelas, ainda conforme a autora, lançam-se na 
luta pela habitação popular. Vítimas das consequências estruturais do sistema como desemprego, baixa remuneração, ausência de imóveis compatíveis com suas rendas e outras precariedades, interagem com os diferentes agentes sociais das instâncias estatais, político-partidárias, religiosas, dentre outras, para fazer jus ao uso do solo onde deram início às construções de suas moradias. A negociação integra desde a legalização do terreno aos aspectos básicos de infraestrutura, como fornecimento de água e energia elétrica com tarifa reduzida.

A terceira forma de organização popular nomeada por Gohn (2005, p.36) são as Associações e Movimentos Comunitários: "não se organizam muito em entidades demarcadas, mas em coletivos unificados por regiões geográficas”. A mobilização envolve os setores mais espoliados da sociedade, as reivindicações giram em torno da noção de direitos. Há uma divisão interna do trabalho, com coordenadores, comissões, abrangendo agentes eclesiais de base, líderes comunitários e várias assessorias. O posicionamento político perante as autoridades é de igualdade nas falas e nos atos.

Em São Caetano, grande parte da mobilização por espaços de Educação Infantil assemelha-se à última forma de organização popular, geralmente, sendo representada por mães ou lideranças da comunidade. Apresenta, concomitantemente, traços do modelo das Sociedades Amigos de Bairros ou Associação de Moradores, porque suas lutas pairam nos resultados imediatos sem o enfrentamento político com o Estado, característica importante das Associações e Movimentos Comunitários. Tudo é aceitável desde que não haja suspensão do uso do equipamento coletivo almejado, por isso a doação ou troca de favores são muito presentes e sempre bem-vindas. Existe também, uma rede de cooperação, mas todas as ações permanecem no universo local das necessidades.

O aparecimento de espaços alternativos de creches e pré-escola no bairro se inscreve no contexto da década de 1980, período que houve uma estagnação econômica, perda da qualidade de vida da população com 
aumento do número de desempregados e da criminalidade, doenças infantis, aumento dos sem teto, sem terra, que persiste até os nossos dias.

Ao mesmo tempo, a opressão sócio-política provocada pelo regime da ditadura foi substituindo, aos poucos, pela aprendizagem de se organizar e reivindicar. Uma das bandeiras era a construção de uma Nova Constituição que pudesse abarcar os anseios sociais antes oprimidos. Como corrobora Gohn (2005, p. 58), “[...] do ponto de vista político a década não foi perdida. Ao contrário, ela expressou o acúmulo de forças sociais que estavam represadas até então, e que passaram a se manifestar”. Em relação às demandas da educação escolar, creches e pré-escolas para as crianças de 0 a 6 anos foi um dos pontos de pauta.

Na conjuntura socioeconômica e política delineada acima emergiu a primeira creche em São Caetano, precisamente em 1984. Originou-se pelo empenho da esposa do presidente da Associação de Moradores das ruas Nova de Camurugipe e Fonte da Bica de Baixo em decorrência da solicitação de mulheres que necessitavam trabalhar para garantir o sustento de sua família e não tinham com quem deixar seus filhos pequenos.

A creche atendia crianças de 01 ano a 06 anos e ficava localizada no fundo da casa do presidente da associação. Atendia mais de 50 crianças em turno integral. A manutenção infraestrutural e de gêneros alimentícios era mantida por bazar, doações dos próprios moradores ou favores de alguns políticos pela troca de voto, o trabalho era desenvolvido pela própria fundadora, que ficava responsável, sozinha, por todas as crianças, como relata em entrevista:

Desde os dezoito anos eu sempre trabalhei com criança, sempre ajudando, fazendo trabalho comunitário. Quando a associação foi fundada por mim e por meu ex-marido fiquei dando aula às crianças, aqui em casa, era tipo uma creche o dia todo. Depois com o tempo parei esse trabalho, dei um tempo, mas aí o povo não me deixava em paz, pedindo para eu abrir uma creche. As mães choravam na minha porta dizendo que se eu não abrisse iam pedir esmolas com seus filhos. Eu fui vendo tanta criança e o povo pedindo, que abri aqui no fundo uma creche, uma minicreche inicialmente, e aí o trabalho deu certo. (...) era mais de 
50 crianças que eu não dava conta, peguei um esgotamento físico. ${ }^{2}$

A instituição ainda existe, embora tenha diminuído o seu quantitativo por conta das dificuldades materiais e humanas. Atende à mesma faixa etária inicial, embora, por falta de espaço físico próprio, por um certo período o atendimento ficou sendo realizado na residência da presidente da associação. Atualmente, possui uma sede própria construída em 2006 por doação de alguns comerciantes do bairro e políticos para barganha de voto. A sua construção foi realizada por mutirão dos moradores.

A estrutura física é composta com uma sala grande, um sanitário e uma varanda pequena. Atende, atualmente, 25 crianças, segundo alegação da Presidente da Associação de Moradores, em função de não possuir o tempo que tinha antes, apesar da demanda por um atendimento bem maia amplo. Inclusive, algumas adolescentes fazem rodízio para ficar com as crianças durante o tempo de atendimento, que é das 8 às 18:00 horas. Conforme relato da responsável pela creche: “Tem assim umas jovens, adolescentes de dezesseis [anos] que se prontificam, revezando entre si, tá ali ensinando (...) fazendo um trabalho razoável.”3

De sua origem aos dias atuais, o movimento dos moradores deste perímetro de São Caetano, em relação à reivindicação de subsídios como uma política mais ampla de direito da criança e dever do Estado é ignorado. A Presidente da Associação de Moradores fica dando “jeitinhos” para sanar os problemas, como relata em um dos trechos da sua fala: “assim as mães ajudam no que podem, mandam uma merenda, ajudam no almoço e a gente

\footnotetext{
${ }^{2}$ Entrevista realizada com a coordenadora da Creche da Associação da Rua Nova do Camurugipe e Rua Fonte da Bica de Baixo,em São Caetano, na sua residência, em novembro de 2006.

${ }^{3}$ Entrevista realizada com a coordenadora da Creche da Associação das Ruas Nova Camurugipe e Fonte da Bica de Cima em São Caetano, na sua residência em novembro de 2006.
} 
também tem ajuda da CEASA com a doação das frutas e verduras que eles não conseguem vender” 4 .

Evidenciou-se, também, no decurso da entrevista, uma distorção da finalidade de atendimento dos dois segmentos da Educação Infantil. Em vários momentos o termo "creche" se referia ao aspecto do regime de horário das crianças - turno integral, embora atendesse crianças de 04 a 06 anos. Equívoco verificado nas demais instituições comunitárias visitadas no bairro.

Além dessas instituições, existem outras duas denominadas de 'creche' por atender em turno integral. Uma emergiu pela iniciativa de três irmãs da Capelinha de São Caetano. A outra foi criada a partir do movimento do Clube de Mães a Serviço da Vida e da Esperança de uma igreja evangélica, fundada em 13/03/2000, situa-se próximo à Baixa do Camurugipe. Ambas atendem em média 60 crianças e surgiram por necessidades distintas, apesar de o pano de fundo ter sido a substituição da ausência das figuras materna e/ou paterna, enquanto estavam cumprindo sua jornada de trabalho.

A instituição Creche-Escola Didática Arco-Íris que se autodenomina comunitária, localiza-se na Capelinha de São Caetano e nasceu pelo desejo de três irmãs que gostavam de ensinar crianças e aproveitaram este sentimento para atender à demanda existente. Atende crianças de 1 ano e 7 meses ao Ensino Fundamental. Segundo entrevista realizada com a diretora não atende berçário por causa da ausência de espaço e condições materiais para recebê-los, mesmo com a grande procura pelos responsáveis de crianças nessa faixa etária.

Para manter o atendimento cobra uma taxa mensal aos pais e recebe uma contribuição da AEEC (Associação dos Educadores das Escolas Comunitárias), como relata em seu depoimento:

\footnotetext{
${ }^{4}$ Mercado que vende frutas, legumes e outros gêneros alimentícios em Salvador. Consideramos preocupante a qualidade dos produtos que o mercado "não consegue vender”.
} 
Por ser comunitária nós cobramos uma taxa menor que da redondeza, pra a gente manter o aluguel, as meninas também, porque elas fazem um trabalho voluntário, mas nós damos uma gratificação a elas mensal então agente precisa dos pais em relação à isso e ao aluguel.

Agora nós recebemos uma contribuição da AEC (Associação das Escolas Comunitárias), mas é um dinheiro anual, é uma ajuda que eles dão pra as escolas, geralmente em dezembro, janeiro, fora isso a gente vai "empurrando com a barriga"(....) .

A Instituição comunitária originada pelo Clube de Mães a Serviço da Vida e da Esperança, localiza-se em uma área muito violenta, inclusive, esta é uma das justificativas de sua implantação, como resgatado no seu memorial:

A priori, o surgimento do Clube de Mães ocorreu por meio de reivindicações dos moradores em relação à existência de uma escola-creche que atendesse a necessidade das mães que trabalhavam e não tinham com quem deixar seus filhos.

Em decorrência dessa situação as crianças estavam vivendo um processo de marginalização(...). Preocupadas com esse fato, um grupo de mães resolveu se reunir e então propuseram a fundação de uma Escola-Creche, como sendo uma solução para o problema das famílias que não tinham como educar seus filhos, devido ao trabalho de tempo integral. (MEMORIAL DA CRECHE SERVIÇO DA VIDA E ESPERANÇA, 2000, p. 1)

A creche se mantém com os recursos de uma ONG italiana Ágatha Esmeralda, pelo repasse da prefeitura de 3\%, que, segundo depoimento da coordenadora, é anual e irregular e por doações esporádicas de alimentos, através do projeto Prato Amigo vinculada a ONG Mais Social. A instituição tem um computador, DVD e televisor, materiais tecnológicos raros nas outras instituições comunitárias, fruto dos subsídios financeiros das próprias mães, que contribuem com quanto e quando podem, e alguns recursos das ONGs. Na fala da coordenadora ficou evidente o envolvimento emocional com seu trabalho, tentando sozinha minimizar a situação precária das crianças, em um "espírito maternal”, mesmo na sua ingênua forma de “cuidado” e zelo:

\footnotetext{
${ }^{5}$ Entrevista realizada em junho de 2007, na sede da instituição, na Capelinha de São Caetano.
} 
É muito menino, e aí todo dia tem gente lá na porta: 'oh! Pelo amor de Deus me ajude', que a gente sabe a realidade, né? Têm algumas mães que contribuem, outras não contribuem, são zero oitocentos, então eu sou aquela mãe que se preocupa com aqueles, que eu chamo de meus filhos, né? São meus filhos. Eu não quero que ninguém faça nada, porque são meus filhos que eu tomo assim do coração porque...(emociona-se $)^{6}$

Esta fala da coordenadora, bem como as intenções que impulsionaram a sua criação, como explicitado no seu memorial, revela a "preocupação" como um fenômeno alienante das relações humanas frente à realidade objetiva. KOSIK (1976) afirma que a atitude de “preocupação” substitui a categoria “trabalho" como um processo criador e transformador das ações do homem em relação ao seu meio, manifestando-se à consciência diária como um mundo já pronto e provido de aparelhos, equipamentos, relações e contatos, em que os indivíduos, isoladamente, através da ocupação (ação meramente reprodutora), busca dar respostas direta e imediata aos problemas que parecem ser desconectados com a totalidade, cuja a origem está oculta.

Montaño (2002) também delineia a função social de intervenção do “ator voluntário" como um agente que deixa de ser sujeito, passando a se materializar num sistema supra-histórico. Deixa-se levar pelo princípio que “já não se faz a (nem se pensa na) história, mas apenas em estórias, singulares e cotidianas” (MONTAÑO, 2002, p. 243).

Percebe-se em todas as mobilizações por instituições de Educação Infantil no bairro uma tentativa de cada um de forma isolada sanar suas dificuldades. A concepção da creche comunitária como um princípio democrático da cogestão, em que se integram comunidade e Estado para realização da atividade de serviço à criança, como preconizado por Castro (1991), é substituída pela visão neoliberal de ações individuais e a prática da parceria precária com as organizações não governamentais, camuflando os interesses políticos e contradições de classe.

Montaño (2002) aponta uma perspectiva contra hegemônica de

\footnotetext{
${ }^{6}$ Entrevista realizada na residência da coordenadora da creche, em agosto de 2007.
} 
articulação da sociedade civil que comunga com a concepção ampliada de Estado em Gramsci: a mobilização, como lutas sociais, por direitos sociais. Neste movimento, a participação da comunidade não é concebida como gerenciadora de recursos e executora dos serviços sociais, mas como luta conjunta, fundamentada e orientada pelas contradições de classes, pressionando e obrigando "Estado e o capital a absorver certas demandas e a incorporá-las como função do Estado” (MONTAÑO, 2002, p. 278).

Partindo desse pressuposto, a mobilização da sociedade civil não é desenvolver ou compensar os serviços sociais que o Estado não assume ou descentraliza para o âmbito privado, mas devem ser lutas com intuito de preservar e ampliar conquistas históricas para suprir as demandas sociais da coletividade, desmascarando os mecanismos e interesses nas esferas do Estado, do mercado, da produção e da própria sociedade civil que tentam manter o controle e privilégio de uma determinada classe hegemônica.

A história da mobilização por creches e pré-escolas em São Caetano, revela medidas paliativas provocadas pela ausência do poder estatal, ainda como iniciada nos anos 70. No cotidiano das famílias de extratos sociais desfavorecidas são essas instituições que vêm suprindo, de fato, as demandas por esses equipamentos coletivos do jeito que podem. Não pode se perder de vista de que forma este atendimento tem funcionado como uma política que respeite os direitos fundamentais da criança.

\section{As distorções do papel da sociedade civil}

O discurso da nova ordem de estruturação capitalista distorce a função da sociedade civil preconizada por Gramsci, para escamotear e manter a desigualdade social de forma dissimulada e incumbir à família, à comunidade e à filantropia o provimento dos direitos sociais como um processo solidário, legítimo e inevitável. Essa forma de intervenção social delega papéis a um chamado "terceiro setor”, fomentado por um sentimento de "comunitarismo", pacificador, a fim de garantir a transferência de responsabilidade do Estado para o âmbito privado no acesso aos bens 
sociais. Desse modo, apazigua o descontentamento da população marginalizada com soluções fragmentadas, pontuais e locais para atingir os objetivos neoliberais de supremacia do mercado financeiro.

É preciso retirar o véu do significado dos conceitos de terceiro setor, comunidade e sociedade civil para esclarecer as formas de "engajamento" e/ou “intervenção" social implementada a partir dos anos 90. Ideias ancoradas no pensamento neoliberal para intensificar a hegemonia da função substitutiva do Estado e consolidação da nova fase produtiva do capital.

Bauman (2000) chama-nos atenção para o perigo do esquecimento da arte de questionar e traduzir os problemas pessoais em questões de ordem pública. Ao veicular o Estado como insustentável, seus porta-vozes expressam a necessidade de autoconfiança, de contar com os próprios recursos na aquisição dos bens sociais para sobrevivência humana. A atitude de repassar para o âmbito pessoal, privado, as questões que afligem aparentemente o individual, enfraquece uma ação para o bem da coletividade em uma ação pública e impessoal de engajamento, participação, pois a necessidade de uma pessoa, uma família, pode ser a necessidade de todos. De acordo com Bauman (2000, p.55), “a insegurança privatizada usa muitas máscaras, mas quase nunca revela sua verdadeira face, que - como rosto da Medusa - só pode ser encarada sob o risco da paralisia”. O autor, também, sinaliza essa nefasta forma de retraimento para a qualidade da luta conjunta:

Uma vez privatizada e entregue aos recursos pessoais a tarefa de lidar com a insegurança existencial humana, os medos que cada um sente só podem ser "contados", mas não partilhados ou unidos numa causa comum com a qualidade nova da ação conjunta. Não há um caminho óbvio que leve dos terrores privatizados às causas comuns que podem se beneficiar do confronto e enfrentamento conjunto. (BAUMAN, 2000, p. 54)

A tentativa de cooptação das massas sempre pode ocorrer, por isso é preciso, nesse território de tensão e luta uma ação autônoma e crítica. Como afirma Bauman (2000), a ambivalência da esfera público-privada como terra 
de muitos donos e de propriedade disputada requer um espaço no qual os conflitos e anseios pessoais tornem-se públicos para decisão do sentido do bem comum.

Para os gregos esse espaço era a ágora, nos dias atuais esse espaço pode ser todos os lugares ocupados pela zona de conflito e concorrência de domínio. Gohn (2005) sinaliza algo importante, como possibilidade de superação da classe oprimida, a ação de uma cidadania coletiva engendrada no interior da prática social através do processo de identidade políticocultural provocada pelas lutas cotidianas. Talvez este seja um caminho para as necessidades pessoais de ordem pública serem explicitadas e desmistificadas do âmbito de questões individuais de caráter privado.

Segundo Montaño (2002), nas décadas de 1980 e 1990 fomentou-se a necessidade de uma zona de intersecção que pudesse dar conta dos anseios da população pela falta de suprimento das políticas sociais. Difundiu-se a ideia, calcada nos pensadores neoliberais, baseada na seguinte premissa: “se o Estado está em crise e o mercado tem uma lógica lucrativa, nem um nem o outro poderiam dar resposta às demandas sociais” (MONTAÑO, 2002, p, 54). Cabia, então, a um suposto setor imparcial da sociedade, suprir as necessidades de educação, saúde, segurança, seguridade social, o responsável seria o terceiro setor. Este setor legitima a primazia do privado no que se refere à oferta dos serviços sociais básicos, principalmente para a população de baixa ou nenhuma renda, por intermédio da privatização do público.

Ainda segundo Montaño (2002), esta zona de intersecção materializa a atividade pública pelo setor privado, delegando às próprias vítimas da exclusão social arcar e executar a prestação dos serviços sociais essências para sua subsistência. A família e a tão enaltecida comunidade, que nada mais é que a reunião molecular de várias famílias, além de seus membros venderem sua força de trabalho e não ganharem o correspondente pelo esforço desempenhado, têm que prover suas necessidades básicas. Estas usurpadas pela falta de repasse dos impostos pagos propiciado pela função 
substitutiva do Estado e pelo excedente dos lucros do mercado e sua lógica de precarização do trabalho.

O autor esclarece que as controvérsias do tipo de instituições que fariam parte do terceiro setor, se movimentos pacíficos ou organizações de lutas de maior impacto e enfrentamento, evidencia e gera ambiguidade no seu papel social, pois ao mesclar diferentes sujeitos como aparentemente iguais camufla o jogo de interesses e as estratégias de manipulação. A fusão de interesses, espaços e significados sociais diversos, contrários e contraditórios, confundem mais que esclarecem a função de sua existência.

A ausência de densidade teórica do termo revela o sentido e a utilidade de encobertar a realidade com o objetivo de agir de forma ideologizada sobre ela. Montaño (2002) delineia o caminho para o "neoliberalismo light”, para o qual convergem autores como Bresser Pereira, já citado nesse trabalho com o discurso de uma terceira alternativa configurada em público não estatal. Os pensamentos de Tocquevillle (18271839) que percebia o Estado como aparato da "tirania da maioria” e Hayek (1977) como o “caminho da servidão”, ambos propagavam a diminuição da esfera estatal. O que esses dois teóricos postulavam em comum era o mercado como regulador da organização social. Os membros da sociedade civil, por sua vez, através de esforços individuais isolados supririam suas necessidades.

Hayek (1977), por sua vez, defendia um sistema social organizado através do livre mercado, como meio para garantir a liberdade individual. Para ele o Estado despreza as diferenças e que a intervenção do mesmo não permitia o "esforço pessoal dos indivíduos”. Para o autor, só o Estado de Direito, no plano formal das leis, é capaz de resguardar a igualdade de oportunidades e não a igualdade real "substitutiva”. Esse Estado de direito, para facilitar a livre concorrência, mantém em alguma medida uma política social-assistencialista, provida de forma precária e dirigida aos indivíduos que não alcançaram a condição de sobrevivência. As outras demandas sociais deveriam ser atendidas de forma descentralizada, providos, 
alternadamente, pelo mercado e entidades assistenciais.

Gera-se, então, na década de 1980, uma rede solidária como efeito de poder, subordinando a vida das pessoas a auxílios pontuais e fragmentados. Tudo em nome da preservação da propriedade privada, enriquecimento e concentração de renda dos detentores dos meios de produção e, sobretudo, livre regulação do mercado. A introdução desse discurso resultou em uma corrente que também está submersa nas práticas do chamado terceiro setor, em voga na atualidade com o objetivo de recuperar as relações humanas e incentivar a integração social das pessoas: o comunitarismo ou o retorno aos laços da comunidade.

A gênese da avalanche comunitarista, segundo Semeraro (1999,) foi desencadeada principalmente nos Estados Unidos, em oposição ao projeto de renovação do liberalismo dos anos 70. Essa concepção procura criticar o individualismo tão aclamado por Haeyk (1977), buscando restaurar os laços familiares, comunitários e nacionais, com o intuito de dissolver a visão contratualista e mercantilista inserida na sociedade atual pelo projeto da modernidade. O homem, na percepção dos comunitaristas deve ser vinculado às suas raízes históricas, étnicas e culturais. Embora o discurso do retorno aos vínculos comunitários seja sedutor em uma sociedade marcada por diversos tipos de discriminação, desemprego, exclusão e perda gradativa do valor da pessoa humana, este novo paradigma pode trazer consigo um conformismo generalizado, uma vez que o respeito às tradições, à paz e à acordos comunitários convencem a naturalização das condições da realidade existente.

Esse retorno aos ideais comunitários traz custos à capacidade humana de enfrentar a dinâmica da vida cotidiana de forma crítica e conflituosa. As questões políticas, econômicas e os mecanismos ideológicos perversos de exclusão são mascarados com o discurso de cidadania solidária. Sennet (1988) alerta-nos que o contato comunitário tenta forjar o desenvolvimento urbano moderno como uma resposta para o desaparecimento das cidades. Estes padrões de vínculos comunitários, no entanto, não despertam qualquer 
desejo de se refazer a própria cidade, apenas alimentam uma fuga com a consecução de 'alternativas', transformando os valores psicológicos em relações sociais.

O incentivo predominante na atualidade é desenvolver a personalidade individual por meio de experiências de aproximação e de calor humano para com os outros, postula-se o mito de que os males da sociedade são decorrentes da impessoalidade, alienação e frieza. Sennet (1988) salienta que a soma desses três aspectos constitui a ideologia da intimidade para justificar o declínio da cultura pública, pois quanto mais os problemas sociais estiverem próximos das preocupações interiores psicológicas de cada pessoa, mais irão encontrar soluções nos domínios privados da vida.

Deduz-se que o clamor pelo retorno aos laços comunitários escamoteia as estruturas políticas mais amplas da sociedade, a fim de manter as contradições do sistema e evitar o confronto. As medidas locais e pontuais assumem o lugar dos embates impessoais e abrangentes de forma ilusória, não dando um poder real à micro localidade da comunidade.

Como estratégia para modificar a postura intimista dos laços comunais, o autor propõe o destemor pela impessoalidade, pois a pessoalidade encoraja a vida coletiva de natureza "paroquial”. As ligações impessoais, por outro lado, obriga as pessoas a conhecerem as outras pessoas a fim de fazer uso do "nós" de forma mais profunda e ampla para atingir toda a sociedade. O medo do desconhecido, segundo Sennet (1988), faz com que as pessoas enfrentem, assimilem e explorem a realidade exterior em escala paroquiana.

A visão comunitarista como solução para os problemas sociais talvez represente uma válvula de escape para fugir do terrível e complicado mundo, bem como uma maneira de compensar as duras exigências de uma ação política transformadora da ordem pública. Semeraro (1999) aponta como um caminho de superação do comunitarismo um dos princípios do pensamento de Gramsci que situa as relações locais e cotidianas num quadro sociopolítico mais amplo, a fim de livrar da estagnação e das possíveis 
manipulações para deixar emergir as disputas políticas e econômicas da divisão social. Para tanto, retoma a concepção gramsciana de sociedade civil.

Por estar submersa em uma correlação de forças, nem tudo que vem da sociedade civil pode ser caracterizado como "bom" (ela pode ser hegemonizada pela classe que oprime), e nem tudo que provém do Estado pode ser visto como "mau" (ele pode expressar as demandas que se originam das classes subalternas). Para compreender as interfaces de domínio, subjugação ou emancipação é preciso fazer uma análise histórica das correlações de forças atuantes em cada momento para definir as potencialidades e função negativas ou positivas tanto da sociedade civil como do Estado.

A sociedade civil, para Gramsci, não está orientada em função do Estado, nem se reduz à obediência das relações econômicas da burguesia, mas é o extenso e complexo espaço da organização social, onde se travam enfrentamentos ideológicos, políticos e culturais que delineiam a hegemonia de um grupo dirigente sobre toda a sociedade.

Diferente da visão liberal-burguesa que concebe a sociedade civil como um lócus do indivíduo separado, tendo como ponto de partida e de chegada o indivíduo, para Gramsci, a sociedade civil é "o terreno onde os indivíduos privados de sua dignidade e fragmentados em suas atividades podem encontrar condições para construir a sua subjetividade e personalidade” (SEMERARO, 199, p. 160). Ao organizar-se livre e criativamente, os sujeitos não desenvolvem apenas suas potencialidades individuais, mas também suas dimensões públicas e coletivas. Partindo desse pressuposto, o percurso é do ser particular para o social.

Diferencia-se do associativismo perpetuado por Tocqueville e os neoliberais, pois há uma coletivação das necessidades materiais, políticas e culturais em dimensão pública. O indivíduo, ainda que seja o centro autônomo das decisões, nunca age isoladamente, mas sempre como um ser dentro de uma concreta trama social, interligado com outros sujeitos livres, 
com os quais se defronta e constrói consensualmente a vida em comum.

A propagação de uma sociedade civil amórfica preconizada pela emergência do terceiro setor e o retorno aos laços comunitários, apenas retrai a participação ativa e consciente de homens e mulheres alijados do processo de construção da sociedade. Como podem agir livremente, se os acordos consensuais entre parceiros de interesses de classes antagônicas convivem pacificamente? É preciso desmistificar as amarras do conformismo para desvelar as estratégias de exclusão. Esse redimensionamento do papel da sociedade civil poderá ser possível com a retirada do véu dos conceitos e a ação transformadora dos protagonistas sociais escondidos, calados, ludibriados do processo de construção da sua realidade concreta.

Entretanto, o associativismo ou a ação do "terceiro setor" intensificado pelo projeto neoliberal, a partir dos anos 90, vem conduzindo, ainda mais, as organizações da sociedade civil a intervir nas próprias demandas locais de sua realidade. Desloca-se, então, para o microssocial com o discurso de "auto responsabilização do cidadão”, “da comunidade local”, “solidariedade social”, “ajuda mútua” para assumir serviços típicos de Estado. Esta forma de intervenção setorizada pode ser observada na história de mobilização por creches e pré-escolas em São Caetano, com a ingerência de iniciativas do âmbito privado na busca de alternativas de interesse público.

\section{Considerações finais}

As discussões presentes neste trabalho, referente às alternativas encontradas pela população na tentativa de suprir a lacuna do Estado na Educação Infantil, possibilitam fazer algumas considerações a partir dos resultados encontrados, no sentido de que se configuram ou não como atendimento ao direito das crianças de 0 a 06 anos. Tais considerações, embora não sejam definitivas, apontam para mudanças e estratégias nas políticas educacionais no município de Salvador, a fim de minimizar a 
permanência em condições de estabelecimentos e práticas que não respeitam as demandas sociais, afetivas, psicomotoras, linguísticas e cognitivas das crianças pequenas.

No estudo, tornou-se evidente que ainda persiste o acesso diferenciado das crianças conforme a origem da classe social a que pertence. Aquelas oriundas das camadas menos favorecidas que não possui condições de escolha, em função da situação socioeconômica de suas famílias, são postas em qualquer tipo de espaço disponível, desde que fiquem protegidos e assistidos. Haja vista que trabalhar para as mulheres desse extrato social não configura apenas um meio de realização profissional, mas de sobrevivência.

As creches e/ou pré-escolas que emergem pelo empenho de comunidades locais funcionam como mecanismos para preencher a lacuna do Estado, incentivando a privatização, uma vez que as próprias famílias assumem financeiramente a sustentação e a continuidade do serviço, deixando de lado a gratuidade que caracteriza a “escola” pública. O discurso de que a comunidade deve arcar com a educação de seus filhos vem servindo como forma de manobra do projeto neoliberal para isentar o Estado na garantia de proteção social, no caso do estudo, em destaque a educação.

O princípio de cogestão e/ou convênio com os Centros de Educação Infantil Comunitários proporciona uma participação proforma, quando não ausente, perante os poderes públicos. Um exemplo desta prática foi o leque de reivindicações sugeridas pelas instituições comunitárias, para incluir no documento Políticas e Diretrizes para o Desenvolvimento Infantil Integral e Integrado no município, a fim de amenizar os problemas infra estruturais e o pagamento de pessoal.

O histórico de mobilização por creches e pré-escolas em São Caetano revelou como o incremento de espaços criados pela própria população não vem promovendo lutas articuladas e amplas para a consolidação da Educação Infantil no município como uma política pública. A busca por soluções imediatistas impossibilita manifestações e pressões para ações coletivas. As ONGs e as próprias famílias assumem a função do Estado com 
ações pontuais e paliativas, escamoteando as mudanças estruturais que desencadeiam esta forma de intervenção social.

A falta de um controle e acompanhamento dos órgãos competentes vem proporcionando a continuidade da educação e cuidados para as crianças de 0 a 06 anos, com um enfoque assistencialista ou partindo do extremo da escolarização precoce, nos moldes do saber hegemônico criticado pelos próprios movimentos da educação popular. A falta de apoio técnicopedagógico e financeiro da Secretaria Municipal de Educação e Cultura tem comprometido ainda mais o fazer pedagógico dessas instituições, pois as políticas de formação não alcançam os profissionais dos CEIC nem em serviço, nem de forma continuada.

O estudo também revelou um forte laço solidário entre os moradores, mesmo com as dificuldades materiais que possuem, criando lideranças e mecanismos de saídas para evitar sucumbir frente às mudanças estruturais do sistema e a falta de oferta dos bens sociais elementares. Apesar de locais, quem sabe possam ecoar como forma de enfrentamento mais amplo e emancipatório.

\section{Referências Bibliográficas}

BASTOS, Eni e PEIXOTO, Maria Solange. Creches comunitárias de Salvador: perfil do serviço In Creche comunitária: uma alternativa popular. Ana Alice Alcântara Costa (org.) Salvador: NEIM/UFBA; EGBA;SEC, 1991.

BAUMAN, Zygmumt. Em busca da politica. Tradução, Marcus Penchel. Rio de Janeiro: Jorge Zahar, 2000.

CAMPOS, Maria M. Histórico da creche. Rio de Janeiro: Fundação Carlos Chagas, 1987.

A legislação, as políticas nacionais de educação infantil e a realidade: desencontros e desafios In: Encontros e desencontros em educação infantil. Maria Lúcia Machado (org.), São Paulo: Cortez, 2000.

FRIEDMAN, Milton e FRIEDMAN, Rose. Liberdade de escolher. Trad. Ruy Jungman. Rio de Janeiro: Editora Record, 1980. 
GONH, Maria da Glória. Movimentos sociais e educação. 6. ed. Revista. São Paulo: Cortez, 2005.

Teorias sobre movimentos sociais na era da globalização: a mobilização política - MP In: Teoria dos movimentos sociais. São Paulo: Edições Loyola, 1985.

HAYEK, Friederich August von. O caminho da servidão. Tradução de Leonel Vallandro. 2 ed. São Paulo, Globo, 1997.

KOSIK, Karel. Economia e filosofia In: A dialética do concreto. Tradução Célia Neves e Alderico Toríbio, 2 ed. Rio de Janeiro, Paz e Terra, 1976.

MONTAÑO, Carlos. Terceiro setor e questão social: crítica ao padrão emergente de intervenção social. São Paulo: Cortez, 2002.

PEREIRA, Luiz Carlos Bresser e GRAU, Nuria C. (Orgs.).Entre o Estado e o Mercado: o público não estatal. In: $O$ público não-estatal na reforma do Estado brasileiro. Rio de Janeiro: Fundação Getúlio Vargas, 1999.

PERONI, Vera. Política educacional e o papel do Estado: no Brasil dos anos 90. São Paulo: Xamã, 2003.

SEMERARO, Giovanni.Gramsci e a sociedade civil; cultura e educação para a democracia. Petrópolis, RJ: Vozes, 1999.

SENNET, Richard. O declínio do homem público: as tiranias da intimidade. Tradução Ligya Araújo Watanabe. São Paulo: Companhia das letras, 1988.

SEVERINO, Antonio Joaquim. O público e privado como categoria de análise em educação In: O público e privado na história da educação brasileira: concepções e práticas educativas. José Claudinei Lombardi, Maria Regina M. Jacomeli, Tânia Maria T. da Silva (orgs.). Campinas, SP: Autores Associados, HISTEDBR, UNISAL, 2005.

SHIROMA, Eneida Oto et all. Política educacional. Rio de Janeiro: DP\&A, 3. ed.2004.

\section{Fontes Documentais}

BRASIL. Constituição Federal de 1988. Brasília.

BRASIL. Lei de Diretrizes e Bases da Educação Nacional. no 9.394 de 1996, Brasília. 